\title{
Pemodelan dan Simulasi Peluang Kebangkrutan Perusahaan Asuransi dengan Analisis Nilai Premi dan Ukuran Klaim Berdistribusi Eksponensial
}

\author{
Farah Diba ${ }^{1}$, Deni Saepudin ${ }^{2}$, Aniq Atiqi Rohmawati ${ }^{3}$ \\ ${ }^{1,2,3}$ Prodi Ilmu Komputasi, FakultasTeknik Informatika, Universitas Telkom \\ Jl. Telekomunikasi Terusan Buah Batu Bandung 40257 Indonesia \\ 1dibafarah0317@gmail.com, \\ 2 denisaepudin@ telkomuniversity.ac.id \\ ${ }^{3}$ aniqatiqi@telkomuniversity.ac.id
}

\begin{abstract}
This study is about modelling and simulation probability of bankruptcy in the insurance company at the time of receiving claims by costumers. The company has the funds to pay claims that derived from accumulated initial reserve and income of insurance from premiums that have payed. If the company's funds at time $t$ is smaller than 0 then the insurance company will going bankruptcy. Therefore will be analyzed the premiums that must be payed by insurance costumers. If the premiums that payed by costumer is greater, so the funds of insurance company will greater too at the time- $t$ to cover the next claims. Probability of bankcruptcy in the insurance company can be predected from the simulation model $n$-times with claims frequency which happened at the time between 0 dan $t$ is assumed distribution Poisson and claim sizes is distribution Exponential.
\end{abstract}

Keywords: bankruptcy probability, Exponential distribution, Poisson distribution, premiums

\section{Abstrak}

Jurnal ini berisi tentang pemodelan dan simulasi peluang kebangkrutan perusahaan asuransi saat menanggung klaim dari pelanggan. Perusahaan mempunyai dana untuk membayar klaim yang diperoleh dari akumulasi cadangan dana awal dan pendapatan perusahaan dari pembayaran premi. Jika dana perusahaan pada waktu ke- $t$ lebih kecil sama dengan 0 maka perusahaan asuransi mengalami kebangkrutan. Oleh karena itu dianalisis premi yang harus dibayar oleh pelanggan asuransi. Semakin besar jumlah premi yang dibayar, maka semakin besar dana perusahaan asuransi pada waktu ke- $t$ untuk menanggung klaim berikutnya. Sehingga dapat diestimasi peluang kebangrutan dengan simulasi model n-kali jika diasumsikan banyaknya klaim yang terjadi pada selang waktu antara 0 dan $t$ berdistribusi Poisson dan ukuran klaim berdistribusi Eksponensial.

Kata Kunci: peluang kebangkrutan, distribusi Eksponensial, distribusi Poisson, premi 
FARAh Diba ET.AL.

Pemodelan dan Simulasi Peluang Kebangkrutan...

\section{PENDAHULUAN}

$S^{\mathrm{s}}$ EBAGIAN besar seseorang menggunakan layanan asuransi untuk mengantisipasi risiko keuangan yang terjadi akibat kejadian tertentu. Kejadian tersebut berupa klaim yang diajukan oleh pelanggan ke perusahaan asuransi. Dalam sistem asuransi, pelanggan mempunyai kewajiban untuk membayar premi sesuai polis dan mempunyai hak atas klaim yang diajukan agar dibayar sesuai kesepakatan bersama. Suatu perusahaan asuransi harus mampu menghitung perkiraan klaim yang akan terjadi, sehingga dapat menentukan berapa besarnya premi yang harus dibayarkan oleh pelanggan untuk mengurangi kerugian yang menyebabkan perusahaan bangkrut [3].

Pendapatan bersih yang diperoleh perusahaan akan berubah dari waktu ke waktu, bergantung pada pada jumlah premi yang masuk dan jumlah klaim yang dibayarkan oleh pelanggan [1-2]. Semakin besar premi yang dibayarkan maka semakin kecil peluang kebangkrutan perusahaan asuransi tersebut.

Ali Deven Sezer (2010) sudah membuat model $S_{t}=S_{0}+(c \times t)-\sum_{i=1}^{N_{t}} X_{i}$ untuk menghitung dana perusahaan pada waktu ke-t. Dari formula tersebut diketahui pendapatan bersih perusahaan diperoleh dari premi dikalikan waktu yang berjalan secara kontinu [9]. Pada Jurnal ini digunakan pendekatan model Ali Deven Sezer (2010) untuk menghitung dana perusahaan pada waktu ke-t. Perbedaan model yang digunakan adalah pada proses pendapatan perusahaan yang diperoleh dari premi dikalikan jumlah pelanggan yang masuk tiap harinya. Model ini berlaku untuk jenis asuransi life insurance dan non-life insurance dengan produk asuransi kesehatan, kendaraan, bangunan, bisnis, pendidikan, dan lain-lain.Sehingga model yang akan digunakan untuk simulasi peluang kebangkrutan adalah $S_{t}=S_{0}+(c \times j)-\sum_{i=1}^{N_{t}} X_{i}$, dengan $j$ adalah jumlah peserta yang mengajukan klaim pada hari ke- $t$.

Semakin besar premi yang dibayarkan maka semakin kecil peluang kebangkrutan perusahaan asuransi. Teori ini berlaku untuk jenis produk asuransi kesehatan, kendaraan, bangunan, dan lain sebagainya. Sehingga dapat ditentukan premi ideal yang harus dibayar pelanggan agar perusahaan asuransi tidak mengalami kebangkrutan. Apabila peluang dana perusahaan pada waktu ke- $t$ lebih kecil sama dengan 0 maka perusahaan asuransi tidak mampu menanggung klaim berikutnya sehingga perusahaan mengalami kerugian yang akan menyebabkan kebangkrutan.

Oleh karena itu, dalam Jurnal ini diimplementasikan model peluang kebangkrutan dari simulasi model yang dilakukan n-kali dengan asumsi banyaknya klaim yang terjadi pada selang waktu antara 0 dan $t\left(N_{t}\right)$ berdistribusi Poisson dan ukuran klaim $\left(X_{i}\right)$ berdistribusi Eksponensial.

\section{DASAR TEORI}

\section{A. Klaim Asuransi}

Klaim asuransi adalah jaminan yang diberikan asuransi kepada pelanggan atas risiko kerugian yang terjadi sesuai dengan kesepakatan bersama. Klaim yang diajukan akan ditinjau validitasnya sesuai dengan peraturan polis asuransi yang telah disepakati bersama. Waktu pengajuan klaim tidak bisa ditentukan kapan saja klaim tersebut datang. Sehingga akan digunakan distribusi Eksponensial untuk menganalisis waktu kedatangan klaim. Klaim yang digunakan sebagai bahan pengujian adalah frekuensi klaim atau banyaknya klaim yang terjadi pada satuan waktu tertentu, sehingga analisis distribusi Poisson akan digunakan untuk mengantisipasi banyaknya klaim yang terjadi pada waktu tertentu [2-3].

\section{B. Premi}

Premi adalah uang yang harus dibayarkan pelanggan atas klaim yang telah diajukan. Premi ditentukan sesuai dengan polis atas kesepakatan bersama antar perusahaan dan pelanggan asuransi. Premi yang dibayar oleh pelanggan merupakan pendapatan bersih perusahaan. Untuk mengurangi kerugian dan meminimumkan peluang kebangkrutan, perusahaan asuransi hendak mempunyai cadangan dana awal. Salah satu faktor untuk mengetahui perusahaan asuransi mengalami kebangkrutan atau tidak adalah dengan estimasi besar premi. Semakin besar premi yang dibayarkan oleh pelanggan maka semakin kecil peluang kebangkrutan perusahaan asuransi.

Premi dapat memberikan tambahan cadangan dana perusahaan selain berasal dari cadangan dana awal yang telah dimiliki oleh perusahaan asuransi sebelumnya. Untuk simulasi peluang kebangkrutan akan digunakan estimasi premi sebagai acuan untuk menentukan peluang kebangkrutan perusahaan asuransi. 


\section{Distribusi Poisson}

Percobaan Poisson adalah banyaknya hasil selama selang waktu atau daerah tertentu yang menghasilkan peubah acak $X$ yang bernilai numerik. Panjang selang waktu boleh semenit, sehari, sebulan, atau bahkan setahun. Banyaknya hasil $X$ pada suatu percobaan Poisson disebut suatu peubah acak Poisson dan distribusi peluangnya disebut distribusi Poisson. Proses Poisson adalah proses menghitung (counting process) untuk kejadian yang terjadi hingga suatu waktu. Proses Poisson sering disebut juga dengan proses lompatan (jump process) karena keadaan akan berpindah ke yang lebih tinggi setiap kali kejadian terjadi [3-5].

Suatu peubah acak $X$ dikatakan sebagai peubah acak Poisson dengan parameter $\lambda$ jika, untuk $\lambda>0$, memiliki fungsi peluang

$$
P(X=k)=e^{-\lambda} \frac{\lambda^{k}}{k !} ; k=0,1 \ldots
$$

$X_{i}$ dengan $i=1,2,3, \ldots$, Jika $N_{(t)}$ adalah banyaknya klaim yang terjadi dalam interval waktu $[0, t], N_{(t)}$ diasumsikan sebagai peubah acak diskrit sebanyak $N_{(t)}$ yang saling bebas dan identik, sehingga menurut definisi proses menghitung $N_{(t)}$ adalah counting process. Proses menghitung $N_{(t)}$ harus memenuhi :

1. $N_{(t)} \geq 0$

2. $N_{(t)}$ bernilai bilangan bulat (integer)

3. Jika $t_{1} \leq t_{2}$ maka $N_{t_{(1)}} \leq N_{t_{(2)}}$

4. Untuk $t_{1} \leq t_{2}$ maka $N_{t_{(2)}}-N_{t_{(1)}}$ sama dengan banyaknya peristiwa yang terjadi pada interval $\left(t_{1}, t_{2}\right]$

Definisi lain mengenai peubah acak Poisson adalah banyaknya kejadian pada interval dengan panjang $t$ adalah peubah acak Poisson dengan parameter $\lambda$ t. Sehingga proses menghitung $\{N(t), t \geq 0\}$ dikatakan sebagai proses Poisson dengan intensitas $\lambda, \lambda>0$ jika :

1. $N(0)=0$

2. Proses memiliki kenaikan bebas (independent increment)

3. Banyaknya peristiwa dalam beberapa interval sepanjang $t$ berdistribusi Poisson dengan mean $\lambda \mathrm{t}$. Untuk setiap $s, t \geq 0$

$$
P\{N(t+s)-N(s)=n\}=e^{-\lambda t} \frac{\lambda t^{k}}{k !} ; k=0,1 \ldots
$$

Berdasarkan definisi diatas, dapat dikatakan bahwa $\{N(t), t \geq 0\}$ merupakan peubah acak yang berdistribusi Poisson yang memiliki nilai ekspektasi seperti dibawah ini dan $\lambda$ menunjukkan laju dari proses Poisson

$$
E[N(t)]=\lambda \mathrm{t}
$$

\section{Distribusi Eksponensial}

Waktu antar kedatangan klaim pada asuransi mengalami proses Eksponensial yang berperan penting dalam teori antrian dan teori keandalan (realibilitas). Distribusi Eksponensial saling berhubungan dengan distribusi Poisson. Ronald E Walpole dan Raymond H Myers (1995) menjelaskan hubungan proses Eksponensial yang saling berhubungan dengan proses Poisson. Bahwa proses Poisson digunakan untuk menghitung peluang jumlah khusus ‘kejadian' selama jangka waktu atau selang tertentu [10-12]. Dalam banyak hal, jangka waktu atau selang berbentuk peubah acak, misalnya perusahaan asuransi yang ingin meneliti waktu tiba kedatangan klaim yang diajukan pelanggan pada suatu waktu tertentu. Waktu tiba disini merupakan kejadian Poisson [13].

Hubungan antara distribusi Eksponensial dan proses Poisson cukup sederhana. Poisson diturunkan sebagai distribusi berparameter tunggal dengan parameter $\lambda$, disini $\lambda$ dapat ditafsirkan sebagai rataan banyaknya kejadian per satuan 'waktu'. Misalkan $T_{1}$ menyatakan waktu kejadian atau kedatangan pertama. Untuk $n>1$, misalkan $\mathrm{T}_{\mathrm{n}}$ menyatakan waktu tersisa kejadian ke- $(n-1)$ dan kejadian ke- $n$. Barisan $\left\{\mathrm{T}_{\mathrm{n}}, n=1,2, \ldots\right\}$ adalah barisan waktu antar kejadian (interrarival times). Untuk menentukan distribusi dari $\mathrm{T}_{\mathrm{n}}$, kejadian $\left\{\mathrm{T}_{1},>\right.$ $t$ \} terjadi jika dan hanya jika tidak ada kejadian dari proses Poisson yang terjadi pada interval $[0, t]$. Dengan 
FARAh Diba ET.AL.

Pemodelan dan Simulasi Peluang Kebangkrutan...

menggunakan distribusi Poisson kita peroleh bahwa peluang tidak ada kejadian yang muncul dalam jangka waktu t diberikan oleh [6-8]:

$$
p(0 ; \lambda \mathrm{t})=e^{-\lambda \mathrm{t}} \frac{(\lambda \mathrm{t})^{0}}{0 !}=e^{-\lambda \mathrm{t}}(2.1)
$$

Jadi $T_{1}$ berdistribusi Eksponensial dengan mean $1 / \lambda$. Misalkan $X$ adalah waktu sampai kejadian Poisson yang pertama. Peluang bahwa jangka waktu sampai kejadian pertama melampaui $x$ sama dengan peluang bahwa tidak ada kejadian Poisson yang muncul dalam waktu x. Sehingga akan sama dengan dengan $e^{-\lambda t}$. Dengan demikian

$$
P(X \geq \mathrm{x})=e^{-\lambda \mathrm{t}}
$$

$N(t)$ adalah banyaknya klaim yang masuk sampai waktu t. Jika $W_{n}=\sum_{i=1}^{n} T_{i}=T_{1}+T_{2}+T_{3}+\cdots+T_{n}$, yaitu waktu penantian sampai dengan klaim ke $\mathrm{n}$ terjadi. Misal $T_{i}$ independen dan berdistribusi identik yang berbentuk Eksponensial dengan parameter $\lambda$, yaitu $T_{1} \sim \operatorname{EXP}(\lambda)[3]$.

Misalkan $T_{i}=x$, maka PDF (Probability Density Function) dari $T_{i}$ adalah

$$
f(x)=\lambda e^{-\lambda t}
$$

\section{E. Model Peluang Kebangkrutan Perusahaan Asuransi}

Sebelum menentukan peluang kebangkrutan akan dicari terlebih dahulu model dana perusahaan pada waktu ke- $t$ untuk menanggung klaim yang diajukan oleh pelanggan. Kemudian digunakan analisis premi sebagai acuan simulasi dana perusahaan pada waktu ke-t. Semakin kecil premi yang dibayar pelanggan maka semakin besar peluang kebangkrutan perusahaan asuransi. Oleh kerena itu digunakan pendekatan model yang telah dibuat Ali Deven Sezer (2010) dengan menghitung pendapatan bersih perusahaan yang diperoleh dari premi dikalikan dengan waktu. Berikut pendekatan model yang telah dikembangkan oleh Ali Deven Sezer untuk menghitung dana perusahaan asuransi pada waktu $t$ [9], yaitu sebagai berikut:

Keterangan :

$$
S_{t}=S_{0}+c t-\sum_{i=1}^{N_{t}} X_{i}
$$

$S_{t} \quad$ : Dana perusahaan pada waktu ke- $t$

$S_{0}$ : Cadangan dana awal perusahaan

$c \quad$ : Premi yang diperoleh secara kontinu dengan laju pertumbuhan konstan per satuan waktu

$t \quad$ : Waktu

$N_{t}$ : Banyaknya klaim yang terjadi pada selang waktu 0 dan $t$

$X_{i} \quad$ : Ukuran klaim ke- $i$

Terdapat pembedaan model yang akan digunakan untuk simulasi peluang kebangkrutan pada penelitian ini. Perbedaan tersebut berada pada cara perhitungan pendapatan perusahan asuransi. Berdasarkan model (5) untuk menghitung pendapatan perusahaan diperoleh dari premi yang dikalikan dengan waktu. Sedangkan perhitungan pendapatan yang akan digunakan pada simulasi ini diperoleh dari premi dikalikan dengan jumlah pelanggan asuransi. Oleh karena itu akan diperoleh pemasukan perusahaan asuransi dari akumulasi cadangan dana awal ditambah dengan pendapatan bersih yang berasal dari premi yang dikalikan dengan jumlah pelanggan asuransi. Berikut model yang telah dibuat berdasarkan pendekatan model (5) yaitu sebagai berikut:

Keterangan :

$$
S_{t}=S_{(t-1)}+(c \times j)-\sum_{i=1}^{N_{t}} X_{i}
$$

$S_{t} \quad:$ Dana perusahaan pada waktu ke- $t$

$S_{(t-1)}$ : Cadangan dana perusahaan yang diperoleh dari dana perusahaan sebelumnya

$N_{t} \quad$ : Banyaknya klaim yang terjadi pada selang waktu antara 0 dan $t$

$X_{i} \quad$ : Ukuran klaim ke- $i$ 
Setelah dilakukan perhitungan dana pada waktu ke-t, selanjutnya akan dihitung peluang kebangkrutan perusahaan asuransi. Semakin besar dana yang dimiliki oleh perusahaan, maka semakin kecil peluang kebangkrutan perusahaan tersebut. Pada saat kondisi dana perusahaan kurang dari sama dengan 0, maka perusahaan asuransi tidak mempunyai dana untuk menanggung klaim yang masuk sehingga perusahaan asuransi akan mengalami kerugian yang menyebabkan kebangkrutan. Oleh karena itu, perusahaan asuransi harus mempunyai dana lebih besar sama dengan 0 agar dapat menanggung banyaknya klaim $\left(N_{t}\right)$ yang diajukan oleh pelanggan asuransi. Dibawah ini merupakan model ruin probability atau peluang kebangkrutan perusahaan asuransi sebelum waktu $T$ besar [9], yaitu sebagai berikut :

$$
P\left(\min _{t \leq T} S_{t} \leq 0\right)
$$

\section{PERANCANGAN SISTEM}

\section{A. Data}

Data yang digunakan dalam Jurnal ini adalah data klaim perusahaan asuransi X dengan produk asuransi kesehatan pada bulan Januari sampai bulan Desember 2014 sebanyak 956480 klaim. Kemudian klaim tersebut akan dianalisis berdasarkan frekuensi klaim yang terjadi pada selang waktu 0 dan $t$, sehingga diperoleh banyaknya klaim yang harus ditanggung oleh perusahaan adalah selama 365 hari atau satu tahun. Kemudian akan digunakan cadangan dana awal dan rate premi untuk menghitung dana perusahaan asuransi per hari. Karena keterbatasan data cadangan dana awal dan rate premi yang merupakan rahasia perusahaan maka akan diasumsikan cadangan dana awal dan rate premi untuk simulasi peluang kebangkrutan dari model yang telah dibuat.

\section{B. Perancangan Sistem}

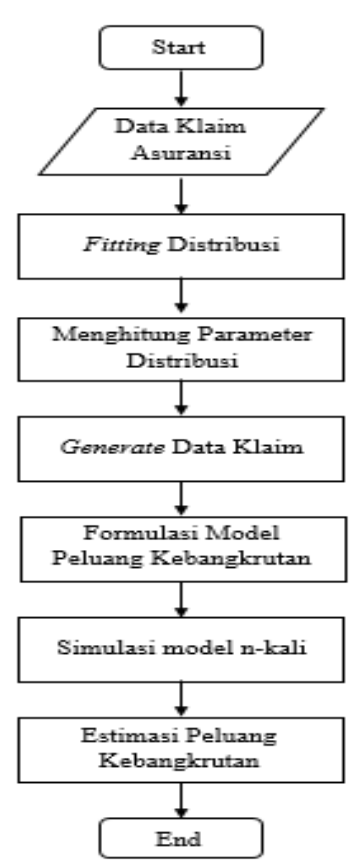

Gambar. 1. Flowchart Simulasi Peluang Kebangkrutan 
FARAh Diba ET.AL.

Pemodelan dan Simulasi Peluang Kebangkrutan...

Penjelasan rancangan sistem pada simulasi peluang kebangkrutan, yaitu sebagai berikut :

1. Data Klaim Asuransi

Pada tahap ini akan digunakan data klaim asuransi untuk mengetahui hasil fitting distribusi pada data klaim tersebut.

2. Fitting Distribution

Pada tahap ini akan dilakukan fitting distribusi atau uji kesesuaian distribusi pada data klaim asuransi, yaitu terhadap ukuran klaim $\left(X_{i}\right)$ dan terhadap banyaknya klaim yang terjadi pada selang waktu 0 dan $t$ $\left(N_{t}\right)$. Tujuan fitting distribusi ini adalah untuk menentukan apakah ukuran klaim dan banyaknya klaim yang masuk per hari sesuai dengan indikator yang diperoleh dari suatu distribusi yang telah diasumsikan sebelumnya.

3. Menghitung Parameter Distribusi

Dari hasil fitting distribusi, selanjutnya akan dihitung parameter sesuai dengan asumsi distribusi Eksponensial pada ukuran klaim $\left(X_{i}\right)$ dan distribusi Poisson pada banyaknya klaim yang masuk per hari $\left(N_{t}\right)$.

4. Generate Data Klaim

Pada tahap ini dilakukan generate ukuran klaim $\left(X_{i}\right)$ yang berdistribusi Eksponensial dan frekuensi klaim $\left(N_{t}\right)$ yang berdistribusi Poisson sesuai dengan parameter yang telah diketahui.

5. Formulasi Model Peluang Kebangkrutan

Kemudian memodelkan peluang kebangkrutan berdasarkan model yang telah dijelaskan pada Bab 2, formula model (2.6).

6. Simulasi Model n-kali

Pada tahap ini dilakukan simulasi n-kali terhadap model peluang kebangkrutan yang telah dibuat.

7. Peluang Kebangkrutan

Pada tahap ini, setelah dilakukan simulasi n-kali diestimasi peluang kebangkrutan perusahaan asuransi dari berdasarkan model yang telah dibuat.

\section{PEMBAHASAN}

A. Analisis Premi dan Proporsi Peluang dengan $S_{0}=R p 10.000 .000 .000$

Berikut hasil pengujian premi dengan proporsi peluang yang telah diperoleh, yaitu sebagai berikut:

Tabel. 1. Analisis Premi dan Proporsi Peluang dengan $S_{0}=$ Rp10.000.000.000

\begin{tabular}{|c|c|c|c|}
\hline No & Premi & Peluang Bangkrut & Rata-rata Hari Pertama Bangkrut \\
\hline 1 & 4000 & 1 & 10 \\
\hline 2 & 4200 & 1 & 10 \\
\hline 3 & 4400 & 1 & 11 \\
\hline 4 & 4600 & 1 & 11 \\
\hline 5 & 4800 & 1 & 11 \\
\hline 6 & 5000 & 1 & 12 \\
\hline 7 & 5200 & 1 & 12 \\
\hline 8 & 5400 & 1 & 13 \\
\hline 9 & 5600 & 1 & 13 \\
\hline 10 & 5800 & 1 & 13 \\
\hline 11 & 6000 & 1 & 13 \\
\hline
\end{tabular}




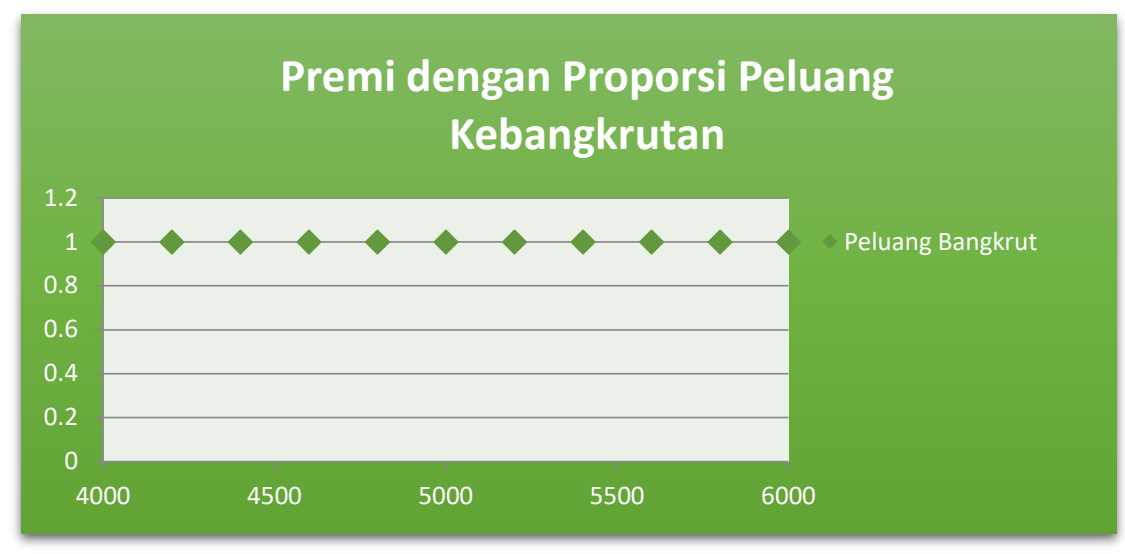

Gambar. 2. Plot Premi dan Proporsi Peluang Kebangkrutan dengan $\mathrm{S}_{0}=\mathrm{Rp} 10.000 .000 .000$

Berdasarkan hasil simulasi 100 kali terhadap model dana perusahaan pada waktu ke- $t$ dengan cadangan dana awal Rp 10.000.000.000, dapat ditentukan peluang kebangkrutan berdasarkan analisis premi yang dibayar oleh pelanggan asuransi. Dari hasil simulasi 11 premi yang diasumsikan, perusahaan asuransi mengalami kebangkrutan pada seluruh premi. Pada simulasi premi Rp 4000 perusahaan asuransi bangkrut dengan peluang 1 dan cadangan dana perusahaan telah negarif dihari ke-10. Artinya perusahaan asuransi tidak dapat menanggung klaim dihari ke-11 dan hari berikutnya.

Begitu juga dengan simulasi premi terbesar yaitu Rp 6000. Dari hasil simulasi dengan premi Rp 6000 perusahaan asuransi juga mengalami kebangkrutan. Hanya saja perusahaan asuransi lebih lama 3 hari mengalami kebangkrutan dibandingkan dengan simulasi premi Rp 4000, yaitu bangkrut dihari ke-13.

B. Analisis Premi dan Proporsi Peluang dengan $S_{0}=R p 358.000 .000 .000$

Berikut hasil pengujian premi dengan proporsi peluang yang telah diperoleh, yaitu sebagai berikut:

Tabel 2 Analisis Premi Dan Proporsi Peluang dengan $\mathrm{S}_{0}=\mathrm{Rp} 358.000 .000 .000$

\begin{tabular}{|c|c|c|c|}
\hline No & Premi & Peluang Bangkrut & Rata-rata Hari Pertama Bangkrut \\
\hline 1 & 4000 & 0,18 & 360 \\
\hline 2 & 4200 & 0,15 & 360 \\
\hline 3 & 4400 & 0,11 & 361 \\
\hline 4 & 4600 & 0,09 & 362 \\
\hline 5 & 4800 & 0,08 & 362 \\
\hline 6 & 5000 & 0,06 & 362 \\
\hline 7 & 5200 & 0,05 & 362 \\
\hline 8 & 5400 & 0,04 & 363 \\
\hline 9 & 5600 & 0,03 & 363 \\
\hline 10 & 5800 & 0,01 & 363 \\
\hline 11 & 6000 & 0 & 0 \\
\hline
\end{tabular}


FARAh Diba ET.AL.

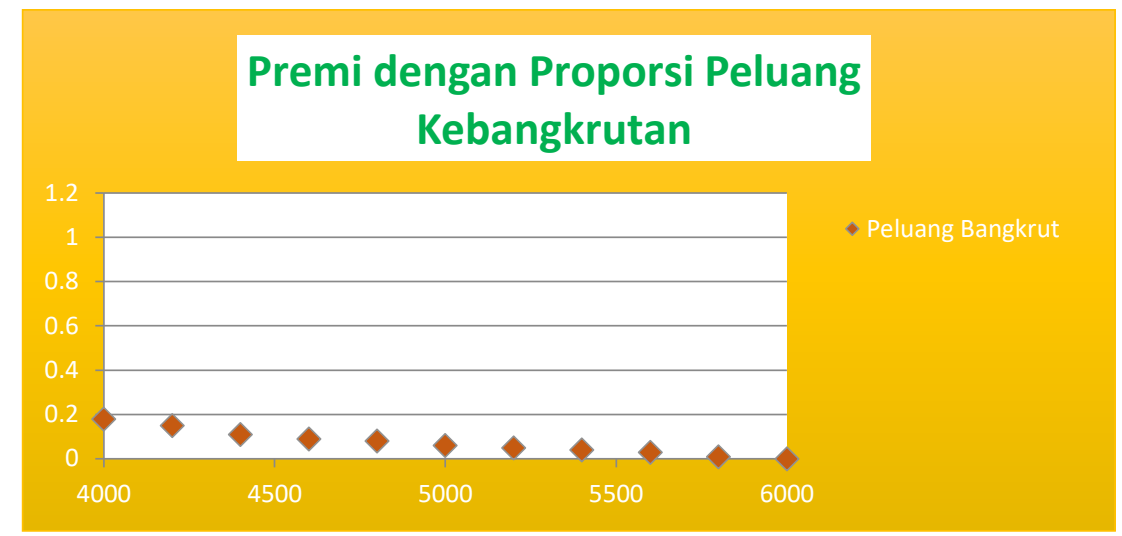

Gambar. 3. Plot Premi dan Proporsi Peluang Kebangkrutan dengan $\mathrm{S}_{0}=\mathrm{Rp} 358.000 .000 .000$

Berdasarkan hasil simulasi 100 kali terhadap model dana perusahaan pada waktu ke- $t$ dengan cadangan dana awal Rp 358.000.000.000, dapat ditentukan peluang kebangkrutan berdasarkan analisis premi yang dibayar oleh pelanggan asuransi. Pada Tabel 2 peluang kebangkrutan yang terbesar adalah dengan premi sebesar Rp 4000 dengan peluang 0,18 dan perusahan asuransi bangkrut pada hari ke-360. Artinya dana perusahaan asuransi sudah negatif pada hari 360 dan tidak dapat menanggung klaim dihari ke-361 dan hari berikutnya. Sehingga perusahaan asuransi akan mengalami kerugian yang menyebabkan kebangkrutan.

Kemudian dapat dilihat pada pembayaran premi sebesar Rp 6000 adalah pembayaran premi terbesar dengan hasil peluang terkecil yaitu sebesar 0. Artinya perusahaan asuransi tidak mengalami kebangkrutan jika perusahaan membebankan premi sebesar Rp 6000 kepada pelanggan asuransi. Hal ini membuktikan bahwa semakin besar premi yang dibayar maka semakin kecil peluang kebangkrutan perusahaan. Karena perusahaan asuransi mempunyai cadangan dana yang lebih besar yang diperoleh dari akumulasi cadangan dana awal dan pendapatan bersih yang diperoleh dari pembayaran premi pelanggan. Sehingga dengan premi Rp 6000 perusahaan dapat mengurangi kerugian dengan meminimumkan peluang kebangkrutan menjadi 0 atau tidak terjadi kebangkrutan pada proses asuransi selama satu tahun.

\section{Kesimpulan}

Berdasarkan hasil implementasi dan analisis yang dilakukan pada simulasi peluang kebangkrutan, maka dapat ditarik kesimpulan bahwa dengan simulasi premi sebesar Rp 4000, diketahui perusahaan asuransi bangkrut pada hari ke-10 dan dengan simulasi premi sebesar Rp 6000 perusahaan asuransi lebih lama bangkrut yaitu pada hari ke-13. Hal ini dapat disimpulkan bahwa semakin besar premi yang dibayar pelanggan maka semakin lama waktu perusahaan asuransi bertahan dalam menanggung klaim dengan jumlah pelanggan yang masuk adalah konstan per harinya. Sehingga, hal ini akan berpengaruh terhadap peluang kebangkrutan yang semakin kecil, karena perusahaan asuransi mendapatkan pemasukan yang lebih besar dari pembayaran premi pelanggan. 


\section{REFERENSI}

[1] Sezer, A.D., 2010. Modeling of an insurance system and its large deviations analysis. Journal of computational and applied mathematics, 235(3), pp.535-546.

[2] Heilpern, S., 2014. Ruin measures for a compound Poisson risk model with dependence based on the Spearman copula and the exponential claim sizes.Insurance: Mathematics and Economics, 59, pp.251-257.

[3] Zuharioh, F., 2015. Perhitungan Premi dengan Asumsi Waktu Antar Klaim Berdistribusi Eksponensial. Matematika dan Statistika serta Aplikasinya,2(1).

[4] Buchori, A., Shodiqin, A. and Istikaanah, N., Peluang Kebangkrutan Perusahaan Asuransi dimana Waktu Antar Kedatangan Klaim Menyebar Eksponensial.

[5] Bølviken, E., 2014. Computation and Modelling in Insurance and Finance. Cambridge University Press.

[6] Burren, D., 2013. Insurance demand and welfare-maximizing risk capital-Some hints for the regulator in the case of exponential preferences and exponential claims. Insurance: Mathematics and Economics, 53(3), pp.551-568.

[7] Walpole, R.E. and Myers, R.H., 1995. Ilmu peluang dan Statistika untuk Insinyur dan Ilmuwan. Bandung: Penerbit ITB.

[8] Naudts, J. and Suyari, H., 2015. Large deviation estimates involving deformed exponential functions. Physica A: Statistical Mechanics and its Applications, 436, pp.716-728.

[9] Sezer, Ali Devin. "Modeling of an insurance system and its large deviations analysis." Journal of computational and applied mathematics 235.3 (2010): 535-546.

[10] Tan, V.Y., Anandkumar, A., Tong, L. and Willsky, A.S., 2011. A large-deviation analysis of the maximum-likelihood learning of Markov tree structures. Information Theory, IEEE Transactions on, 57(3), pp.1714-1735.

[11]Duffield, N.G., 2000. A large deviation analysis of errors in measurement based admission control to buffered and bufferless resources. Queueing systems, 34(1-4), pp.131-168.

[12] Dickson, David CM. Insurance risk and ruin. Cambridge University Press, 2005. 
